\title{
Sildenafil improves clinical and functional status of an elderly postmenopausal female with 'out of proportion' PH associated with left heart disease
}

\section{Terapia con Sildenafil migliora clinica e stato funzionale di una anziana donna con ipertensione polmonare associata a patologia del cuore sinistro}

\author{
Michele Correale, Antonio Totaro, Armando Ferraretti, \\ Matteo Di Biase, Natale Daniele Brunetti
}

\begin{abstract}
Sildenafil improves clinical and functional status of an elderly postmenopausal female with 'out of proportion' PH associated with left heart disease. M. Correale, A. Totaro, A. Ferraretti, M. Di Biase, N. Daniele Brunetti.

We report a case of an elderly woman with heart failure with preserved ejection fraction and pulmonary hyper-
\end{abstract}

tension (HFpEF-PH), refractory to conventional therapy for left heart failure and successfully treated by sildenafil.

Keywords: sildenafil, pulmonary hypertension, left heart failure, diastolic heart failure.

Monaldi Arch Chest Dis 2013; 80: 193-194.

Department of Cardiology, University of Foggia, Foggia, Italy.

Corresponding author: Michele Correale, Department of Cardiology; "Ospedali Riuniti” OO.RR; viale L Pinto, 1; I-71100 Foggia, Italy;Tel 0881733652; Fax0881745424; E-mail address: opsfco@tin.it

\section{Case}

A seventy-two years old woman, with arterial hypertension, diabetes mellitus, permanent atrial fibrillation and previous mitral commisuroplasty for rheumatic mitral stenosis, was admitted to our Department, after a new decompensated heart failure (WHO functional class III-IV).

An echocardiographic examination showed dilated right chambers, left ventricle with D-shaped configuration, moderate mitral stenosis (mean PG: 9 $\mathrm{mmHg}$ ), moderate aortic regurgitation, severe tricuspid regurgitation and the continuous-wave Doppler showed a peak velocity consistent with a pressure gradient of $95 \mathrm{mmHg}$ and a pulmonary arterial systolic pressure (PAsP) of $115 \mathrm{mmHg}$. Right heart catheterization showed a high mean pulmonary arterial pressure (mPAP $80 \mathrm{mmHg}$ ) and high pulmonary arterial wedge pressure (PWP 30mmHg) with transpulmonary gradient (TPG) $>12 \mathrm{mmHg}$ (mean PAP - mean PWP: $50 \mathrm{mmHg}$ ). She performed the six minutes walking test and walked 230 meters ( $53 \%$ of predicted value).

In ambulatory setting, the therapy for left heart failure was most titrated; however, she remained in WHO functional class III and she refused cardiac surgery evaluation. So, we started therapy with sildenafil $10 \mathrm{mg}$ die (with slow titration up to $60 \mathrm{mg}$ die). After one month of sildenafil therapy, she began to improve functional and clinical status $(260 \mathrm{~m}$ at the
6MWT and WHO functional class II-III) with a reduction of the PAsP (95 $\mathrm{mmHg}$ ). After four months of therapy, she received up to sildenafil $60 \mathrm{mg}$ die and further functional status improved (WHO functional class II). After 6 months no major events (hospitalization, cardiac death, death) was observed.

\section{Discussion}

Pulmonary hypertension with elevated TPG occurs in patients with mitral stenosis, and is significantly more common in females [1].

Most of the advances in the treatment of PH have been made in PAH, while a few progress has been made for the $\mathrm{PH}$ due to left heart diseases. Despite the lack of data, drugs with proven efficacy in PAH are increasingly being used for other forms of $\mathrm{PH}$.

Recent studies suggest the usefulness of sildenafil, a phosphodiesterase-5 inhibitor in particular subgroups. In fact, sildenafil appears to be well tolerated and can improve markers of cardiovascular and pulmonary function in patients with HF. So, the PDE5 inhibitors may be a therapeutic option for patients who cannot tolerate standard therapy for HF or who remain symptomatic with standard therapy, as in this case [2].

Sildenafil improves exercise capacity and quality of life in patients with systolic HF with secondary $\mathrm{PH}$ [3] and improves left ventricular diastolic function, cardiac geometry, and clinical status in patients with stable systolic heart failure [4]. 
However, contrast data come from subgroup with HFpEF. In fact, in a multicenter, double-blind, placebo-controlled, parallel-group, randomized clinical trial with 216 stable outpatients with $\mathrm{HFpEF}$, the authors showed administration of sildenafil for 24 weeks, compared with placebo, did not result in significant improvement in exercise capacity or clinical status [5].

Instead, we report a case of an elderly postmenopausal female with residual mitral stenosis post-commissurotomy and permanent atrial fibrillation, where the therapy for left heart failure was most titrated, but, she remained in WHO functional class III. So, sildenafil therapy was performed and she began to improve functional and clinical status with a reduction of the PAsPs. After four months of therapy, she received up to sildenafil $60 \mathrm{mg}$ die and further functional status improved (WHO functional class II).

Over the last decade there has been growing interest in using phosphodiesterase-5 (PDE-5) inhibitors in $\mathrm{HF}$ associated with group 2 pulmonary hypertension $(\mathrm{PH})$, with benefits reported on pulmonary haemodynamic and functional status only in a single-centre trials [3], however our data seem to confirm it.

Further studies to assess sildenafil efficacy and tolerability in patients with $\mathrm{HF}$ and evidence of group $2 \mathrm{PH}$ are necessary, so recently, a randomized, placebo-controlled multinational trial designed to assess this aim in patients with HF (WHO functional class II or III) and evidence of group $2 \mathrm{PH}$ was designed and we looking forward the results [6].

\section{Riassunto}

Riportiamo il caso di una donna anziana con scompenso cardiaco a preservata frazione d'eie- zione ed ipertensione polmonare, refrattario alla terapia convenzionale per lo scompenso cardiaco sinistro e trattato con successo con sildenafil.

\section{References}

1. Hart SA, Krasuski RA, Wang A, Kisslo K, Harrison JK, Bashore TM. Pulmonary hypertension and elevated transpulmonary gradient in patients with mitral stenosis. $J$ Heart Valve Dis 2010 Nov; 19(6): 708-15.

2. Cvelich RG, Roberts SC, Brown JN. Phosphodiesterase type 5 inhibitors as adjunctive therapy in the management of systolic heart failure. Ann Pharmacother 2011 Dec; 45(12): 1551-8.

3. Lewis GD, Shah R, Shahzad K, Camuso JM, Pappagianopoulos PP, Hung J, Tawakol A, Gerszten RE, Systrom DM, Bloch KD, Semigran MJ. Sildenafil improves exercise capacity and quality of life in patients with systolic heart failure and secondary pulmonary hypertension. Circulation 2007 Oct 2; 116(14): 1555-62.

4. Guazzi M, Vicenzi M, Arena R, Guazzi MD. PDE5 inhibition with sildenafil improves left ventricular diastolic function, cardiac geometry, and clinical status in patients with stable systolic heart failure: results of a 1-year, prospective, randomized, placebo-controlled study. Circ Heart Fail 2011 Jan; 4(1): 8-17.

5. Redfield MM, Chen HH, Borlaug BA, Semigran MJ, Lee KL, Lewis G, LeWinter MM, Rouleau JL, Bull DA, Mann DL, Deswal A, Stevenson LW, Givertz MM, Ofili EO, O'Connor CM, Felker GM, Goldsmith SR, Bart BA, McNulty SE, Ibarra JC, Lin G, Oh JK, Patel MR, Kim RJ, Tracy RP, Velazquez EJ, Anstrom KJ, Hernandez AF, Mascette AM, Braunwald E; RELAX Trial. Effect of phosphodiesterase-5 inhibition on exercise capacity and clinical status in heart failure with preserved ejection fraction: a randomized clinical trial. JAMA 2013 Mar 27; 309(12): 1268-77.

6. Cooper TJ, Guazzi M, Al-Mohammad A, Amir O, Bengal T, Cleland JG, Dickstein K. Sildenafil in Heart failure (SilHF). An investigator-initiated multinational randomized controlled clinical trial: rationale and design. Eur $J$ Heart Fail 2013 Jan; 15(1): 119-22. 